\title{
Selective mGluR1 Antagonist EMQMCM Inhibits the Kainate-Induced Excitotoxicity in Primary Neuronal Cultures and in the Rat Hippocampus
}

\author{
Maria Śmiałowska $\cdot$ Krystyna Gołembiowska • \\ Małgorzata Kajta • Barbara Zięba • \\ Anna Dziubina $\cdot$ Helena Domin
}

Received: 7 March 2011 /Revised: 7 November 2011/Accepted: 23 November 2011/Published online: 6 December 2011

(C) The Author(s) 2011. This article is published with open access at Springerlink.com

\begin{abstract}
Abundant evidence suggests that indirect inhibitory modulation of glutamatergic transmission, via metabotropic glutamatergic receptors (mGluR), may induce neuroprotection. The present study was designed to determine whether the selective antagonist of mGluR1 (3-ethyl-2methyl-quinolin-6-yl)-(4-methoxy-cyclohexyl)-methanone methanesulfonate (EMQMCM), showed neuroprotection against the kainate (KA)-induced excitotoxicity in vitro and in vivo. In in vitro studies on mouse primary cortical and hippocampal neuronal cultures, incubation with KA $(150 \mu \mathrm{M})$ induced strong degeneration [measured as lactate dehydrogenase (LDH) efflux] and apoptosis (measured as caspase-3 activity). EMQMCM $(0.1-100 \mu \mathrm{M})$ added $30 \mathrm{~min}$ to $6 \mathrm{~h}$ after KA, significantly attenuated the KAinduced LDH release and prevented the increase in caspase-3 activity in the cultures. Those effects were dose- and timedependent. In in vivo studies KA $(2.5 \mathrm{nmol} / 1 \mu \mathrm{l})$ was unilaterally injected into the rat dorsal CA1 hippocampal region. Degeneration was calculated by counting surviving neurons in the CA pyramidal layer using stereological
\end{abstract}

M. Śmiałowska $(\bowtie) \cdot$ B. Zięba $\cdot$ H. Domin

Department of Neurobiology, Institute of Pharmacology,

Polish Academy of Sciences, Smętna 12,

31-343 Kraków, Poland

e-mail: nfsmialo@cyf-kr.edu.pl

K. Gołembiowska · A. Dziubina

Department of Pharmacology, Institute of Pharmacology,

Polish Academy of Sciences, Smętna 12,

31-343 Kraków, Poland

\section{Kajta}

Department of Experimental Neuroendocrinology, Institute of Pharmacology, Polish Academy of Sciences, Smętna 12, 31-343 Kraków, Poland methods. It was found that EMQMCM $(5-10 \mathrm{nmol} / 1 \mu \mathrm{l})$ injected into the dorsal hippocampus $30 \mathrm{~min}, 1 \mathrm{~h}$, or $3 \mathrm{~h}$ (the higher dose only) after KA significantly prevented the KA-induced neuronal degeneration. In vivo microdialysis studies in rat hippocampus showed that EMQMCM $(100 \mu \mathrm{M})$ significantly increased $\gamma$-aminobutyric acid (GABA) and decreased glutamate release. When perfused simultaneously with KA, EMQMCM substantially increased GABA release and prevented the KA-induced glutamate release. The obtained results indicate that the mGluR1 antagonist, EMQMCM, may exert neuroprotection against excitotoxicity after delayed treatment ( $30 \mathrm{~min}$ to $6 \mathrm{~h}$ ). The role of enhanced GABAergic transmission in the neuroprotection is postulated.

Keywords Neuroprotection - Metabotropic glutamate receptors - EMQMCM - mGlu1 antagonist - Kainic acid . Excitotoxicity

\section{Introduction}

Glutamate is a major excitatory neurotransmitter in the mammalian brain (Watkins and Evans 1981). It acts at different receptor types: ionotropic (iGluRs) (NMDA, AMPA, and kainate) and metabotropic (mGluRs). It is well established that glutamatergic overactivation may lead to neurodegeneration by the mechanism of excitotoxicity (Olney 1978; Choi 1994; Olney and Ishimaru 1999). The excitotoxic cell death has been observed in many brain disorders, such as epilepsy, ischemia, stroke, or trauma (Choi 1988, 1994).

Although experiments on animals have demonstrated neuroprotective effects of the iGluR antagonists in the central nervous system injury, however, they cause many adverse effects, like ataxia, sedation, psychosis, and 
memory loss (Muir and Lees 1995; Danysz and Parsons 1998; Ikonomidou and Turski 2002), which makes them useless in the clinic. Hence, an indirect inhibitory modulation of the glutamatergic transmission seems to be more promising neuroprotective strategy than the direct antagonism at iGluRs (Byrnes et al. 2009). Such indirect modulation may be engendered by the compounds acting on mGluRs. Metabotropic GluRs have been divided into three groups, based on sequence homology and signal transduction mechanisms (Pin and Duvoisin 1995). Group I receptors are coupled to phospholipase $\mathrm{C}$ via $\mathrm{Gq}$ and their activation leads to phosphoinositide hydrolysis and intracellular mobilization of $\mathrm{Ca}^{2+}$ ions. Receptors of groups II and III are coupled to Gi and negatively regulate adenylyl cyclase activity but differ in their pharmacological properties (Conn and Pin 1997; Allen et al. 2000; Spooren et al. 2003)

Many evidences suggest that mGluRs may be a potential targets for neuroprotective drugs (Nicoletti et al. 1996; Bruno et al. 2001). Experimental studies have shown neuroprotective effects after pharmacological activation of group II and III mGluRs which decreased glutamatergic transmission (Bruno et al. 1996, 1997; Gasparini et al. 1999). On the contrary, group I mGluR activation enhanced glutamatergic excitation, and thus neuroprotection was observed after antagonists of these receptors (Bruno et al. 1995; Rao et al. 2000; Flor et al. 2002). Group I mGluRs include mGlu1 and mGlu5 receptors. The discovery of selective mGluR agonists and antagonists opened new perspectives for studying the role of individual receptor subtypes and their importance as potential therapeutics (Spooren et al. 2003). The results indicated neuroprotective effect of mGluR5 antagonists in different animal models (Bruno et al. 2000; Bao et al. 2001; Popoli et al. 2004; Lea et al. 2005). Also our previous studies demonstrated neuroprotective activity of the selective mGluR5 antagonist, MTEP, against kainic acid (kainate)induced excitotoxicity. This effect was observed even after delayed treatment, administered 3-6 h after the onset of intoxication (Domin et al. 2006, 2010). Less is known about mGluR1 ligands and the role of these receptors is still controversial (Nicoletti et al. 1999; Allen et al. 2000). Whereas the antagonists have shown neuroprotective activity (Bruno et al. 1999; Faden et al. 2001; Cozzi et al. 2002), the agonists may induce both neurotoxicity or neuroprotection in different experimental designs (Copani et al. 1995; Nicoletti et al. 1999; Allen et al. 2000). Therefore, further studies on the neuroprotective potential of compounds acting at mGlu1 receptors seem to be very important. In the last years, a novel highly selective uncompetitive mGlu1 receptor antagonist (3-ethyl-2-methyl-quinolin-6-yl)-(4-methoxy-cyclohexyl)-methanone methanesulfonate (EMQMCM) was synthesized
(Lesage et al. 2002) and its neuroprotective effects were evidenced in some hypoxia-ischemia models (Makarewicz et al. 2006; Szydlowska et al. 2007). Moreover, the compound was also active in some behavioral experiments, in anxiety, depression, or learning tests (Gravius et al. 2005; Pietraszek et al. 2005; Belozertseva et al. 2007; Kotlinska and Bochenski 2008).

Therefore, in this study, we examined whether EMQMCM can exert a protective action against excitotoxicity induced by kainic acid (KA), with special focus on the efficacy of delayed treatment. The model of KA-induced neurodegeneration was chosen, as a good and validated simulation of various pathological effects of toxic glutamatergic overactivation occurring, e.g., in epilepsy, ischemia, and traumatic injuries (Coyle 1983; Ferkany and Coyle 1983; Wang et al. 2005), because kainic acid acts not only directly by postsynaptic KA receptor stimulation but also by a secondary massive release of endogenous glutamate which activates all Glu receptors and leads to neurodegeneration (McGeer et al. 1978; Ferkany et al. 1982; Ferkany and Coyle 1983). Therefore, the KA intoxication seems to induce wider effects than a specific stimulation of NMDA receptors and thus it more resembles clinical situations. Moreover, the KA-induced neurodegeneration develops slowly which makes it useful for studying delayed neuroprotection (Mazzone et al. 2010; Mazzone and Nistri 2011). For the in vivo studies, KA microinjection into the CA1 hippocampal region was chosen on the basis of our previous studies (Śmiałowska et al. 2003) as this dose and mode of treatment did not induce generalized seizures (some clonic movements of forepaws and mouth were only observed), and the extent of degeneration was limited. The degenerations were evaluated by determination of cell death both in vitro (LDH release) and in vivo (stereological counting of neurons).

While studying the mechanism of neuroprotective effects of EMQMCM, we focused on two problems (1) a possibility of its antiapoptotic effects and (2) its influence on glutamate and $\gamma$-aminobutyric acid (GABA) release. In the first series of experiments, we decided to estimate caspase-3 activation, as it is known that KA induces a strong caspase-3 activation (Liu et al. 2001; Wang et al. 2005; Domin et al. 2006) and our previous and other studies have shown that mGluR I antagonists attenuated this effect. For caspase-3 estimation, we chose an in vitro model because it gave us a possibility of quantitative analysis and studying different doses and time of treatment in one set of experiments. In the second experimental series concerning the mechanism of EMQMCM protective action, the evaluation of GABA and glutamate release in the hippocampus by means of a microdialysis method in freely moving rats was chosen, since some authors suggested that mGluR1 antagonists increased GABA release 
and the effects on glutamate release were not clear (Pellegrini-Giampietro et al. 1999; de Novellis et al. 2003; Musante et al. 2008).

\section{Materials and Methods}

In Vitro Studies: Cortical and Hippocampal Primary Neuronal Cultures

\section{Materials}

The experiments were performed on primary cultures of mouse cortical and hippocampal neurons. Neuronal tissues were taken from Swiss mouse embryos on days 15/16 (for cortical cultures) and 17/18 (for hippocampal cultures) of gestation, and were cultivated essentially as described previously (Brewer 1995; Kajta et al. 2004). Pregnant females were anesthetized with $\mathrm{CO}_{2}$ vapor, killed by cervical dislocation, and subjected to cesarean section to remove fetal brains. The dissected cortical and hippocampal tissues were minced, then gently digested with trypsin [0.1\%; for $15 \mathrm{~min}$ at room temperature (RT); Sigma, USA], triturated in the presence of $10 \%$ fetal calf serum (Gibco, USA) and DNAse I (170 Kunitz units per ml, Sigma, USA), and finally centrifuged for $5 \mathrm{~min}$ at $1,000 \times g$. The cells were then suspended in phenol red-free Neurobasal medium (Gibco, USA) supplemented with 5\% fetal calf serum and plated at a density of $1.5 \times 10^{5}$ cells per $\mathrm{cm}^{2}$ onto poly-ornithine $(0.01 \mathrm{mg}$ per $\mathrm{ml}$; Sigma, USA)-coated multi-well plates (TPP). After 2 days, the culture medium was exchanged to neurobasal medium supplemented with B27 (200 $\mu \mathrm{l} / 100 \mathrm{ml}$; Gibco, USA). This procedure typically yields cultures that contain about $90 \%$ of neurons and $10 \%$ of astrocytes. The cultures were maintained at $37^{\circ} \mathrm{C}$ in a humidified atmosphere containing $5 \% \mathrm{CO}_{2}$ and were cultivated for 8 days prior to the experiment.

\section{Treatment with Drugs}

In order to evoke toxic effects, primary neuronal cultures were exposed to $150 \mu \mathrm{M}$ kainic acid (KA; Tocris, USA), dissolved in redistilled water, for $24 \mathrm{~h}$ (hippocampal cultures) or $48 \mathrm{~h}$ (cortical cultures). The concentration of KA used in our experiments was chosen on the basis of our earlier studies (Kajta et al. 1999; Kajta and Lasoń 2000; Domin et al. 2006) and also other authors research (Shih et al. 2002, 2004). The time-course of kainate effects on caspase-3 activity and LDH release on primary neuronal cultures was worked out and described in our earlier paper (Domin et al. 2006). Selective mGluR1 antagonist (3-ethyl2-methyl-quinolin-6-yl)-(4-methoxy-cyclohexyl)-methanone methanesulfonate [EMQMCM (originally JNJ 16567983, JNJ, Belgium) is a gift, synthesized by Merz Pharmaceuticals, Frankfurt am Main, Germany] at concentrations of $0.1,1,10$, and $100 \mu \mathrm{M}$ was applied $30 \mathrm{~min}, 1 \mathrm{~h}, 3 \mathrm{~h}$, or $6 \mathrm{~h}$, after starting the exposure to KA. EMQMCM concentrations were chosen on the basis of our pilot experiments and a study by Szydlowska et al. (2007). EMQMCM was dissolved in redistilled water. The control cultures were supplemented with the same amount of an appropriate vehicle.

\section{Evaluation of Cell Death and Protection}

\section{Measurement of Lactate Dehydrogenase (LDH) Activity}

In order to quantify cell death, LDH released from damaged cells into the cell culture media was measured $24 \mathrm{~h}$ (hippocampal cultures) and $48 \mathrm{~h}$ (cortical cultures) after starting the treatment with kainate. A colorimetric assay was used, according to which the amount of formazan salt, formed after conversion of lactate to pyruvate and then by reduction of tetrazolium salt, was proportional to $\mathrm{LDH}$ activity in the sample. Cell-free culture supernatants were collected from each well and incubated with the appropriate reagent mixture according to the supplier's instructions (Cytotoxicity Detection Kit, Roche) at RT for $20 \mathrm{~min}$. The intensity of red color formed in the assay and measured at a wavelength of $490 \mathrm{~nm}$ was proportional to $\mathrm{LDH}$ activity and to the number of damaged cells. The data were normalized to the activity of LDH released from vehicletreated cells $(100 \%)$ and expressed as a percent of the control \pm SEM established from $n \geq 6$ wells per one experiment from three separate experiments. Absorbance of blanks, determined as no-enzyme control, has been subtracted from each value.

\section{Measurement of Caspase-3 Activity}

For evaluation of apoptosis, caspase-3 activation was measured. The method was performed according to Nicholson et al. (1995) and Kajta et al. (2005, 2007) in samples treated for $6 \mathrm{~h}$ with the neurotoxic agent KA, alone or in combination with EMQMCM applied $30 \mathrm{~min}$ after KA. After replacing the media with Caspase Assay Buffer (50 mM HEPES, pH 7.4, $100 \mathrm{mM} \mathrm{NaCl}, 0.1 \%$ CHAPS, $1 \mathrm{mM}$ EDTA, $10 \%$ glycerol, and $10 \mathrm{mM}$ dithiothreitol), the cell lysates $\left(25 \mu \mathrm{g}\right.$ per sample) were incubated at $37^{\circ} \mathrm{C}$ with a colorimetric substrate preferentially cleaved by caspase-3-Ac-DEVD-pNA ( $N$-acetyl-asp-glu-val-asp $p$-nitro-anilide; $40 \mu \mathrm{M}$; Sigma, USA). The amounts of $p$-nitro-anilide were continuously monitored over $60 \mathrm{~min}$ with a plate reader (Multiscan, Labsystems). Absorption was measured at $405 \mathrm{~nm}$ and only the data within the linear 
slope of the reaction curve provided consistent measure of caspase-3 activity. To confirm the correlation between signal detection and caspase activity, we used Ac-DEVDCHO (aldehyde substrate; Molecular Probes, USA), which is a specific caspase-3 protease inhibitor. The data were normalized to the absorbance in vehicle-treated cells and expressed as a percent of control \pm SEM established from $n \geq 6$ wells per one experiment from two separate experiments. Absorbance of blanks, determined as no-enzyme control, has been subtracted from each value.

\section{Identification of Apoptotic Cells}

Apoptotic cells were visualized by fluorescent staining using Hoechst 33342 (Molecular Probes, USA) according to Kajta et al. (2007) and Śmiałowska et al. (2009). Cells for those studies were cultured, as described above, on round cover-glasses (Menzel-Glasser, Germany), placed in 24-holes culture plates. The cultures were treated with KA alone, or with KA and the EMQMCM. At $24 \mathrm{~h}$ (hippocampal cultures) or $48 \mathrm{~h}$ (cortical ones) after the start of incubation with KA (or without KA in control groups), the cultures were washed with phosphate buffer saline (PBS), fixed for 20 min with $4 \%$ paraformaldehyde, washed several times in PBS, and then exposed to Hoechst 33342 $(0.6 \mu \mathrm{g} / \mathrm{ml}$ in PBS) for $10 \mathrm{~min}$ at RT. Hoechst 33342 stains condensed DNA fragments characteristic for apoptotic cells. Bright-blue fluorescence of the condensed chromatin was observed under a fluorescence microscope (Nicon Optiphot 2) using a wave length of 330-380 nm. Microphotographs were made using SPOT 32 camera (Diagnostic Instruments, Inc.).

\section{Data Analysis}

The data after normalization as a percentage of control \pm SEM were analyzed using GraphPad Prism 4.0 software. One-way analysis of variance (ANOVA) was used to determine overall significance. Differences between control and experimental groups were assessed with post hoc Tukey test. The level of significance was determined as $P<0.05$.

\section{In Vivo Studies}

\section{Animals}

Male Wistar rats weighing about 250-300 g were used for the experiments. The rats were age-matched and were housed six to a cage on a 12:12 light-dark cycle, with free access to food and tap water. The rats after cannulae implantation were housed singly. During the experiment, all efforts were made to minimize animal suffering and to reduce the number of animals used, in accordance with the Local Bioethical Commission Guide for the Care and Use of Laboratory Animals.

\section{Cannulae Implantation}

The rats were anaesthetized with equithesin and were stereotaxically, bilaterally implanted with chronic guide cannulae aimed at the dorsal hippocampus CA1 region. The guide cannulae (23-gauge stainless steel tubing), secured by dental cement, were anchored to the skull by three stainless steel screws. In order to prevent clogging, stainless steel stylets were placed in the guide cannulae and left until the animals were microinjected.

\section{Drug Treatments}

Seven days after cannulae implantation, the rats were unilaterally microinjected with KA (Tocris, USA) into the dorsal hippocampus CA1 region (coordinates: $A=$ $+5.7 \mathrm{~mm}, L= \pm 2.1 \mathrm{~mm}, H=+7.2 \mathrm{~mm}$ from the interaural line, according to the Paxinos and Watson (1986) stereotaxic atlas. KA was freshly dissolved in $0.1 \mathrm{M}$ phosphate buffer, pH 7.4 and was microinjected unilaterally in a dose of $2.5 \mathrm{nmol} / 1 \mu \mathrm{l}$. Some rats were additionally injected, through the same cannulae with mGluR1 antagonist EMQMCM. EMQMCM was dissolved in redistilled water, and was injected in doses of 1,5 , or $10 \mathrm{nmol} / 1 \mu \mathrm{l}$ into the CA1 region, $30 \mathrm{~min}, 1 \mathrm{~h}, 3 \mathrm{~h}$, or $6 \mathrm{~h}$ after KA. The contralateral hippocampus of each rat was microinjected with a phosphate buffer and redistilled water, respectively, and used as a control side. The dose of KA was chosen on the basis of our earlier study (Śmiałowska et al. 2003). The doses of EMQMCM and time schedule of treatment were chosen on the basis of Domin et al. (2010) which authors showed neuroprotective effects of another group I mGlu receptor, such as mGlu5 antagonist MTEP.

\section{Evaluation of Damage and Protection in CA Region of Hippocampus}

\section{Tissue Preparation and Histology}

Seven days after treatment, the rats were killed by an overdose of pentobarbital, their brains were removed, fixed in cold, buffered $4 \%$ paraformaldehyde for 7 days, and were then immersed in a buffered $20 \%$ sucrose solution for at least 5 days at $4^{\circ} \mathrm{C}$. The brains were then frozen on dry ice, and 30- $\mu \mathrm{m}$ coronal sections were cut at levels containing the dorsal hippocampus (between bregma -2.12 and $-4.30 \mathrm{~mm}$, according to the Paxinos and Watson (1986) atlas. The sections were mounted on glass slides, 
dried, stained with Cresyl Violet, cover-slipped with Permount, and were used for verification of the injection site and for a histological analysis of the lesion.

\section{Stereology}

The total number of neurons in the pyramidal layer of the CA of the dorsal hippocampus was evaluated by stereological counting. The procedures were performed using a microscope (Leica, DMLB; Leica, Denmark) equipped with a projecting camera and a microscope stage connected to an $x y z$ stepper (PRIOR ProScan) controlled by a computer using the Olympus Denmark CAST2 software, as described previously (Ossowska et al. 2005, 2006; Śmiałowska et al. 2009).

Systemic uniform random sampling was used to choose the sections. The first sampling item was randomly taken from the frontal part of the dorsal hippocampus, and all the following sampling items were taken at a fixed distance from the previous one. At least 10-12 sections through the entire length of the dorsal hippocampus were sampled.

The total number of cells $(N)$ in the pyramidal layer of the hippocampal CA region was estimated by measuring the reference volume ( $V_{\text {ref }}$, the area that contains the population of the cells) and the numerical density $\left(N_{v}\right)$ of the cells within the $V_{\text {ref: }}$ :

$N=V_{\text {ref }} \times N_{v}$

The pyramidal layer of the dorsal hippocampus CA region was outlined at a lower magnification $(5 \times)$. CAST2 software provides templates of points in various arrays used in point counting for reference volume estimation. The $V_{\text {ref }}$ value was determined using point counting methods and applying Cavalieri's principle (Gundersen and Jensen 1987) according to the formula:

$V_{\text {ref }}=\sum \mathrm{pi} \times A(\mathrm{pi}) \times t$

where $\sum$ pi is the sum of the number of points (pi) counted, $A$ (pi) is the area associated with each point, and $t$ is the known distance between sections. The area of the counting frame was $A(\mathrm{fr})=3382 \mu \mathrm{m}^{2}$.

For determination of the density of cells in the hippocampal CA region, the computer software generated a random selection of sites within the outlined area, from which the density was determined under higher magnification $(63 \times)$. Cell density $\left(N_{v}\right)$ was estimated using the optical dissector method according to the formula:

$N_{v}=\sum Q / \sum P \times v($ dis $)$

where $\sum Q$ is the sum of cells counted from all the dissector frames, $\sum P$ is the total number of all the dissector points, and $v$ (dis) is the total volume of the dissector.

\section{Data Analysis}

Statistical analysis was carried out using GraphPad Prism 4.00 software. Differences between the control (contralateral) and the KA-lesioned hippokampi (ipsilateral) were compared by a paired two-tailed $t$ test. Differences between KA-lesioned and KA + EMQMCM-treated hippocampi were compared by an unpaired two-tailed $t$ test. $P$ value less than 0.05 was considered statistically significant.

\section{In Vivo Microdialysis Studies}

The rats were anesthetized with ketamine ( $75 \mathrm{mg} / \mathrm{kg}$ i.m.) and xylazine $(10 \mathrm{mg} / \mathrm{kg}$ i.m.) and placed in a stereotaxic apparatus (David Kopf Instruments, Tujunga, CA, USA). The skull was exposed and small holes were drilled for the insertion of the vertical microdialysis probes in the dorsal hippocampus using the following coordinates: $\mathrm{AP}=$ $-3.3 \mathrm{~mm}$ anterior from the bregma; $L=+2.2 \mathrm{~mm}$ lateral from the sagittal suture; and $H=-4.0 \mathrm{~mm}$ ventral from the dura surface according to the Paxinos and Watson (1986) stereotaxic atlas. Microdialysis probes were constructed as described in detail elsewhere (Gołembiowska and Dziubina 2004a, b). One day after the surgery and probe implantation, the inlet of the dialysis probes was connected to a syringe pump (BAS, IN, USA) which delivered an artificial cerebrospinal fluid (aCSF) composed of [in $\mathrm{mM}$ ]: $\mathrm{NaCl} 147, \mathrm{KCl} 4, \mathrm{CaCl}_{2} 2.2 ; \mathrm{pH} 7.4$ at a flow rate of $1.5 \mu \mathrm{l} / \mathrm{min}$. After $3 \mathrm{~h}$ of washing period, when the extracellular level of neurotransmitters became stable, four baseline samples were collected every $30 \mathrm{~min}$. Next, freshly prepared solutions of $\mathrm{KA}(50 \mu \mathrm{M})$ in aCSF was perfused locally through a microdialysis probe for $30 \mathrm{~min}$. EMQMCM $(100 \mu \mathrm{M})$ or KA + EMQMCM in aCSF (EMQMCM was administered simultaneously with kainate) were perfused locally through a microdialysis probe for $30 \mathrm{~min}$. Then the perfusion fluids were switched back to aCSF or EMQMCM for three additional collection periods. The concentration of EMQMCM was chosen on the basis of our in vitro experiments, presented here, as very effective even after $6 \mathrm{~h}$ delay. At the end of the experiment the rats were killed and their brains were examined histologically to validate the correct probe placement.

\section{Analytical Procedure}

Glutamate was measured in dialysates $(20 \mu \mathrm{l})$ after derivatization with 4-dimethylaminoazobenzene-4'-sulfonylchloride (DABS-Cl) at $70^{\circ} \mathrm{C}$ for $12 \mathrm{~min}$, according to Knecht and Chang (1986). Dabsylated amino acids were separated on an Ultrasphere ODS $(4.6 \times 150 \mathrm{~mm}, 3 \mu \mathrm{m})$ column (Supelco, Poznań, Poland) by gradient elution, 
with solvent A (10 mM citric acid, 4\% dimethylformamide) and solvent B (acetonitrile). Dabsylated compounds were detected by measuring an absorbance at $436 \mathrm{~nm}$ using Beckman Amino Acid System Gold with VIS detection.

GABA in extracellular fluid was measured electrochemically after derivatization with OPA/sulfite reagent to form isoindole-sulfonate GABA-derivative. OPA/sulfite reagent was prepared by dissolving $22 \mathrm{mg} o$-phthaldialdehyde (OPA) in $0.5 \mathrm{ml}$ of absolute ethanol. A $0.5 \mathrm{ml}$ volume of $1 \mathrm{M}$ sodium sulfite was added followed by $9 \mathrm{ml}$ of $0.1 \mathrm{M}$ sodium tetraborate adjusted to $\mathrm{pH} 10.4$ with sodium hydroxide. The working OPA/sulfite solution was prepared by diluting $50 \mu \mathrm{l}$ of OPA/sulfite stock solution with $5 \mathrm{ml}$ of water. Precolumn GABA derivatization was performed by mixing $10 \mu \mathrm{l}$ of the working OPA/sulfite with $10 \mu \mathrm{l}$ of microdialysate for $10 \mathrm{~min}$ at RT before analysis. Chromatography was performed using an LC-10 AD pump (Shimadzu Europa GmbH, Warsaw, Poland), an LC-4B aperometric detector with a cross-flow detector cell (BAS, IN, USA), and a HR-80 column $(80 \times 4.6 \mathrm{~mm}$, $3 \mu \mathrm{m}$; ESA Inc., USA). The mobile phase consisted of $100 \mathrm{mM}$ monosodium orthophosphate, $25 \%$ methanol, $\mathrm{pH}$ 4.6. The flow rate was $0.9 \mathrm{ml} / \mathrm{min}$, and the applied potential of a 3-mm glassy carbon electrode was $+600 \mathrm{mV}$ at a sensitivity of $5 \mathrm{nA} / \mathrm{V}$. GABA-derivative peak was compared with respective standard and was processed by Chromax 2005 (Pol-Lab, Warsaw, Poland) software on a personal computer. The obtained values were not corrected for in vitro probe recovery, which was approximately $10 \%$.

\section{Statistical Analysis}

The statistical significance of microdialysis data was calculated using one-way ANOVA for repeated measures, followed by Tukey's post hoc test. The results were considered statistically significant when $P<0.05$.

\section{Results}

\section{Effect of EMQMCM in Primary Cultures}

Application of EMQMCM, the selective mGlu1 antagonist, significantly decreased the KA-induced LDH release in both cortical (Fig. 1a) and hippocampal (Fig. 1c) cultures. The effect was dose- and time-dependent. When EMQMCM was added $30 \mathrm{~min}$ or $1 \mathrm{~h}$ after KA, at concentrations of $0.1,1,10$, and $100 \mu \mathrm{M}$, significant diminution of LDH release (about 20-35\%) in cortical and (about $17-54 \%$ ) in hippocampal cultures was found. Significant inhibition was also observed when EMQMCM at concentrations of 10 and $100 \mu \mathrm{M}$ (but not 0.1 and $1 \mu \mathrm{M}$ ) was applied $3 \mathrm{~h}$ after KA: by $27 \%$ in cortical cultures and by
$32 \%$ in hippocampal ones (Fig. 1a, c). Protective effects also appeared when EMQMCM was applied $6 \mathrm{~h}$ after KA, but only at concentrations $100 \mu \mathrm{M}$ (about 23\% decrease in cortical and about 33\% decrease in hippocampal ones) (Fig. 1a, c). EMQMCM alone, applied into untreated cultures, did not influence LDH activity at any dose studied. The measurement of caspase- 3 activity showed potent activation of that apoptotic enzyme after $6 \mathrm{~h}$ of KA intoxication, reaching ca. $170 \%$ of the control value. Application of EMQMCM $30 \mathrm{~min}$ after $\mathrm{KA}$, at concentrations of $0.1,1,10$, and $100 \mu \mathrm{M}$ prevented the KA-induced increase in caspase- 3 activity in both cortical and hippocampal cultures (Fig. 1b, d). The level of caspase-3 activity after EMQMCM at concentrations of 10 and $100 \mu \mathrm{M}$ reached the control value. EMQMCM alone added to the cultures, did not influence caspase-3 activity.

Morphological Identification of Apoptotic Cells by Hoechst 33342 Staining

Kainate applicated into the cultures at a concentration of $150 \mu \mathrm{M}$ induced the appearance of apoptotic bodies after $24 \mathrm{~h}$ in hippocampal cultures, or $48 \mathrm{~h}$ in cortical ones. The apoptotic bodies were visibly less numerous when EMQMCM was added into cultures $30 \mathrm{~min}$ after KA. Figure 2 presents the results obtained in hippocampal cultures.

Effect of EMQMCM After Intrahippocampal Injection in Vivo

Kainate injected unilaterally in a dose of $2.5 \mathrm{nmol}$ into the CA1 region of the dorsal hippocampus-induced extensive neurodegeneration $(50 \%$ loss) of CA pyramidal neurons (Fig. 3a). Stereological counting showed a strong reduction in the number of neurons in the pyramidal layer of the ipsilateral dorsal hippocampus in comparison to the contralateral side $[t(6)=12.38, P<0.0001$, Fig. 4].

Cresyl violet staining showed that the extent of lesions in the CA pyramidal layer was significantly smaller in animals treated with EMQMCM (Fig. 3c). The effects of EMQMCM were dose- and time-dependent. EMQMCM administered $30 \mathrm{~min}$ after KA at doses of 10 or $5 \mathrm{nmol} / \mathrm{rat}$ caused a significant increase in the number of visible neurons (an increase by 63 and $42 \%$, respectively, to dose) $[t(12)=$ $4.744, P=0.0005$ and $t(11)=3.230, P=0.0080$, respectively] in comparison with KA-lesioned hippocampi (Fig. 4). EMQMCM used in dose of $1 \mathrm{nmol} / \mathrm{rat}$ did not induce any significant protection effect $[t(9)=0.8989$, $P=0.3921$, Fig. 4].

Neuroprotective effect was also observed when EMQMCM at doses of 10 or $5 \mathrm{nmol}$ was injected intrahippocampal $1 \mathrm{~h}$ after KA. The results of stereological counting showed the significant increase in the number of living neurons in CA 


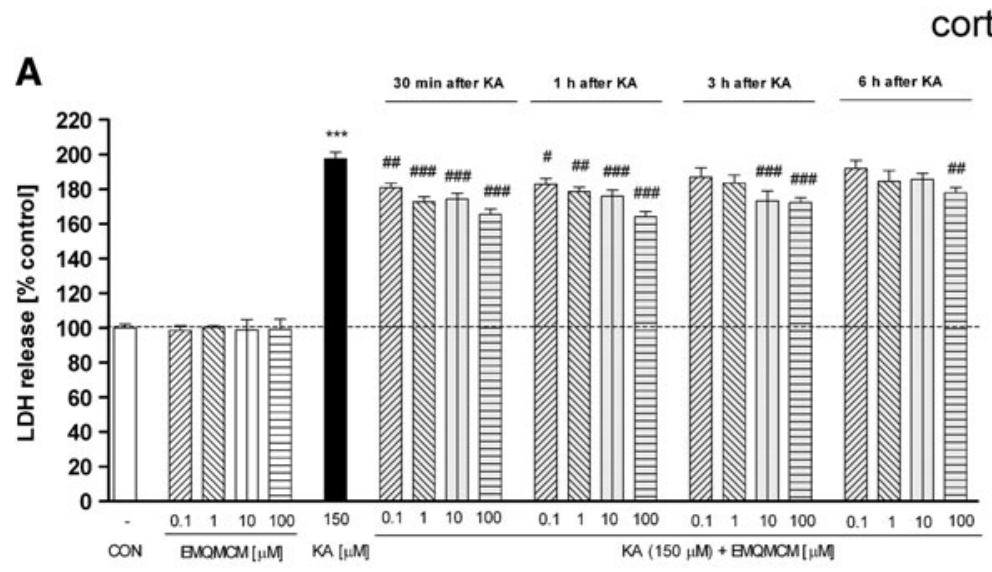

cortical cultures

B

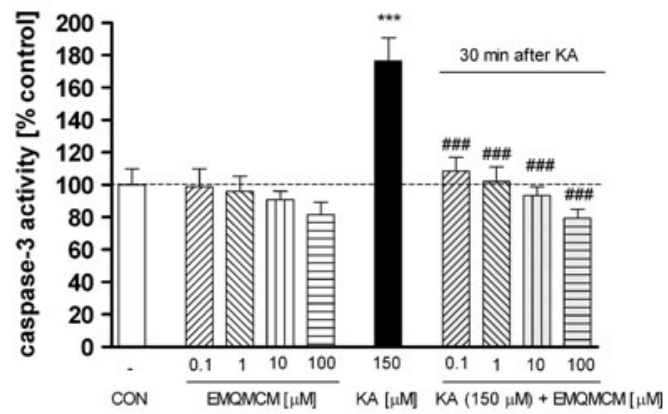

hippocampal cultures
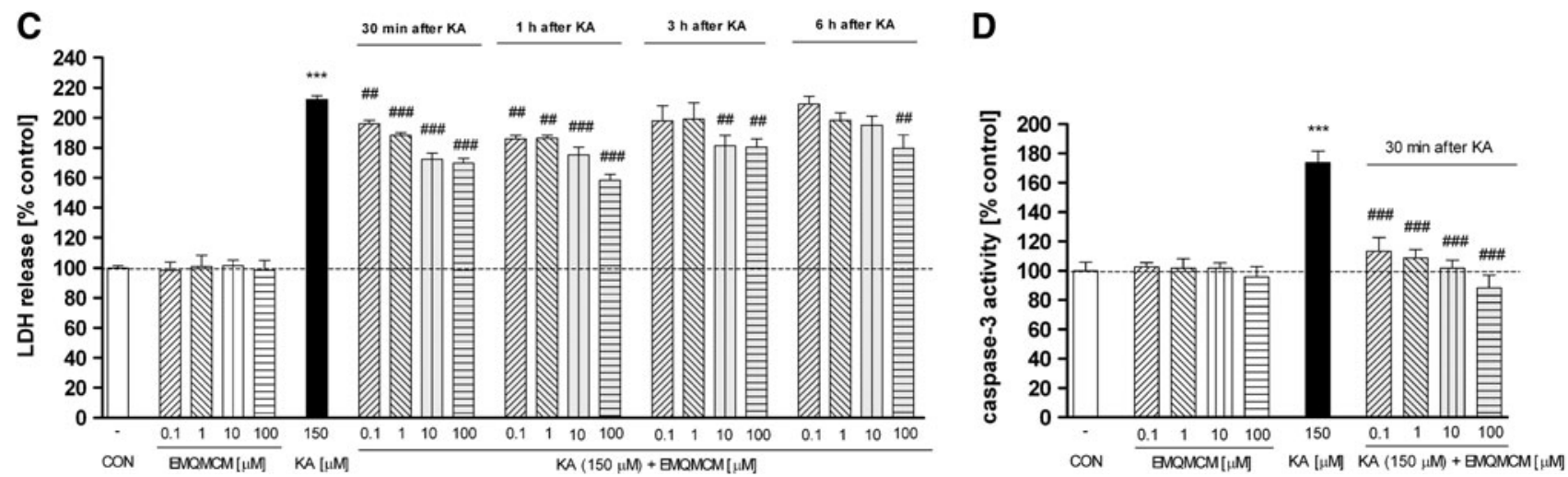

Fig. 1 a, c The effect of EMQMCM on kainate $(150 \mu \mathrm{M})$-induced LDH release in the primary cultures of mouse cortical (a) and hippocampal (c) neurons. LDH was measured $48 \mathrm{~h}$ (cortical) or $24 \mathrm{~h}$ (hippocampal cultures) after KA administration. EMQMCM (in concentrations $0.1,1,10$, and $100 \mu \mathrm{M}$ ) was added to the culture medium $30 \mathrm{~min}, 1 \mathrm{~h}, 3 \mathrm{~h}$, or $6 \mathrm{~h}$ after KA. b, d The effect of EMQMCM on KA-induced increase in caspase-3 activity in mouse

pyramidal layer of the ipsilateral dorsal hippocampus (increase by 69 and $41 \%$, respectively, to dose) $[t(10)=4.847$, $P=0.0007$ and $t(11)=2.605, P=0.0245]$ compared to the KA-lesioned hippocampi (Fig. 4).

A diminution of degeneration was also found when EMQMCM was given $3 \mathrm{~h}$ after KA, but only at dose $10 \mathrm{nmol} / \mathrm{rat}$ (the number of living neurons significantly increased by $38 \%[t(10)=2.620, P=0.0256]$ in comparison to the side with KA alone) (Fig. 4).

Microinjection of EMQMCM $6 \mathrm{~h}$ after KA did not induce any protection $[t(10)=0.4322, P=0.6748$, Fig. 4].

Effect of EMQMCM on Extracellular Level of Glutamate (GLU) and GABA Level in Rat Hippocampus

EMQMCM given into rat hippocampus at concentration of $100 \mu \mathrm{M}$ significantly increased extracellular GABA level in primary cortical (b) and hippocampal cultures (d). Caspase-3 was measured $6 \mathrm{~h}$ after starting KA intoxication. EMQMCM was added to cultures $30 \mathrm{~min}$ after KA. Each bar represents the mean of $n \geq 6$ platings \pm SEM from 3 to 4 independent experiments. Significant differences marked in the following way: $* * * P<0.001$ (vs. control cultures) and ${ }^{\#} P<0.05,{ }^{\# \#} P<0.01,{ }^{\# \# \#} P<0.001$ (vs. KA-treated cultures)

the hippocampal perfusate at 30-120 min after administration with the maximum level (356\% of basal) after $60 \mathrm{~min}$ $[F(1,9)=7.75, P=0.021$, Fig. 5b). Extracellular level of GLU was decreased in comparison to control at 90 and 120 min after the treatment $[F(1,9)=8.13, P=0.0019$; $F(1,9)=16.46, P=0.0028$, respectively] (Fig. 5a).

Kainic acid (KA) perfused locally into the hippocampus at the concentration $50 \mu \mathrm{M}$ for $30 \mathrm{~min}$, induced a significant increase in extracellular GLU level in rat hippocampus at 30, 60, 90, and $120 \mathrm{~min}$ after administration $[F(1,16)=7.73, P=0.013 ; F(1,16)=10.1, P=0.0058$; $F(1,16)=12.64, P=0.0026 ; F(1,16)=3.35, P=0.05$, respectively] (Fig. 6a). Its effect on GABA extracellular level was weaker since significant increase was observed only at $60 \mathrm{~min}$ after administration $[F(1,14)=5.52$, $P=0.038$, Fig. 6b].

When EMQMCM at the concentration $100 \mu \mathrm{M}$ was perfused simultaneously with KA a very strong, significant 

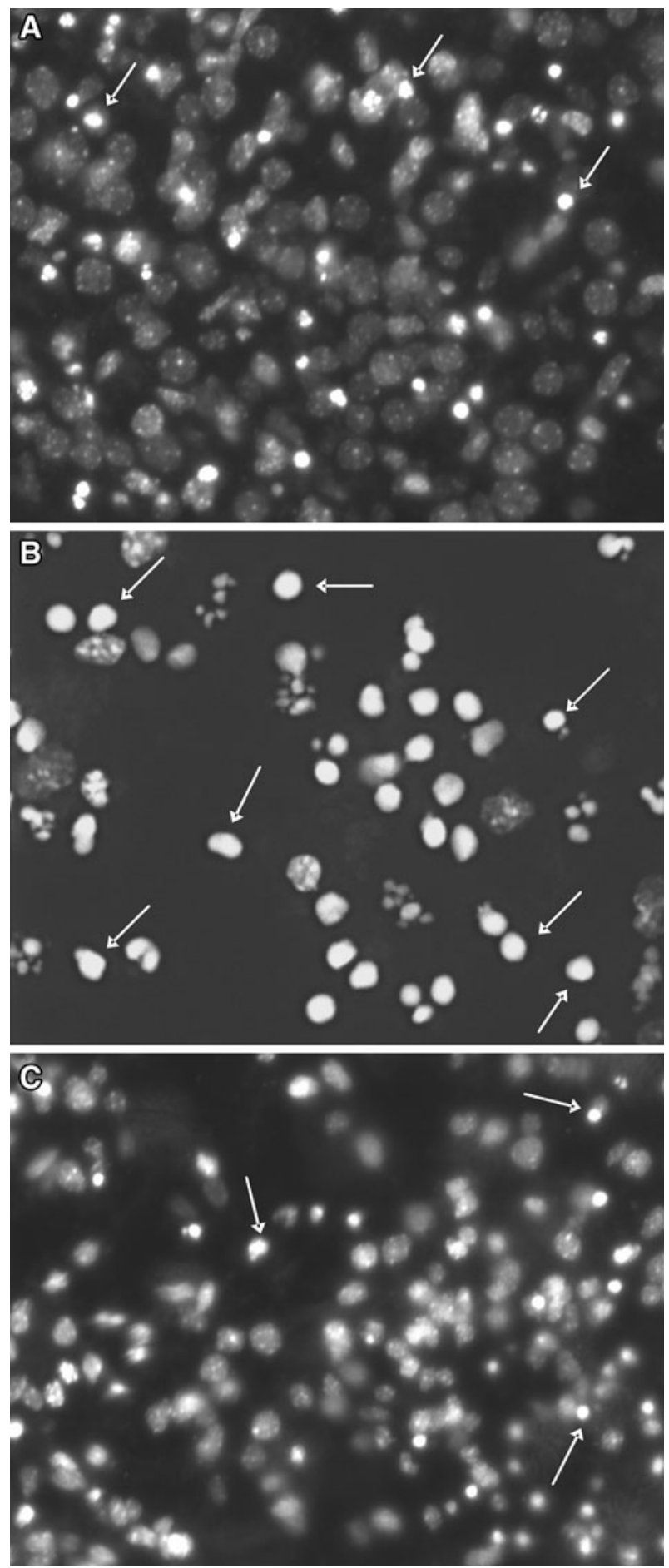

Fig. 2 Selected microphotographs illustrating the fluorescence staining with Hoechst 33342 (a marker of apoptosis) in hippocampal cultures. Cell with bright fragmented nuclei (apoptotic bodies, arrows) showing condensation of chromatin were identified as dying in apoptotic mode. a A control culture with few apoptotic bodies. b A culture after KA exposure $(150 \mu \mathrm{M} ; 24 \mathrm{~h})$; fewer healthy cells and more apoptotic bodies can be seen. c A culture exposed to KA and EMQMCM (100 $\mu \mathrm{M} ; 30$ min after KA); some neuroprotection can be seen as a decrease in the number of apoptotic bodies in comparison with KA (b) increase in GABA level was observed 30-120 min after administration $[F(1,13)=26.22, P=0.0002 ; F(1,13)=$ 5.84, $P=0.036 ; F(1,13)=12.96, P=0.004 ; F(1,13)=$ 16.28, $P=0.002$, respectively] (Fig. 6b). The increase was from $221 \%$ of baseline level after KA to about $471 \%$ when EMQMCM was added. At the same time EMQMCM prevented the KA-stimulated glutamate release $[F(1,12)=$ 4.67, $P=0.05 ; \quad F(1,12)=6.68, P=0.021 ; \quad F(1,12)=$ 16.07, $P=0.001$, respectively] (Fig. 6a).

\section{Discussion}

The obtained results indicate neuroprotective action of the mGluR1 antagonist EMQMCM against KA-induced excitotoxicity. Significant effects were found both in vitro, in the cortical and hippocampal neuronal cultures, and in vivo after their intrahippocampal injection in the rat. EMQMCM is a novel, highly selective uncompetitive antagonist of mGlu1 receptors, easily penetrating the bloodbrain barrier (Lesage et al. 2002). Till now there have been only a few studies on its neuroprotective potential. Szydlowska et al. (2007) have shown a slight neuroprotective action of EMQMCM in vitro in organotypic hippocampal cultures exposed to the mitochondrial toxin 3-nitropropionic acid and in vivo in the middle cerebral artery occlusion model of stroke in rats. The EMQMCM-induced neuroprotection was also found in other ischemic models: 3-min forebrain ischemia in gerbils and hypoxia-ischemia in 7-day-old rats (Makarewicz et al. 2006). These findings are in line with our results showing the neuroprotective action of EMQMCM in the model of kainate toxicity. More studies were performed with other mGluR1 antagonists: AIDA, CBPG，3-MATIDA，CPCCOEt，LY367385, and YM-202074, and their neuroprotective activity was documented (Bruno et al. 1999; Pellegrini-Giampietro et al. 1999; Faden et al. 2001; Cozzi et al. 2002; Kohara et al. 2008; Murotomi et al. 2008). Therefore, our present results and all publications of other authors presented above have indicated that antagonists of mGlul receptors seem to be efficient in protection against neuronal death in different models of neuronal degeneration.

The question if neuroprotection observed in our present study is specifically connected with a blockade of mGlu1 receptors is still open. Szydlowska et al. (2007) suggested that EMQMCM at higher concentrations might interact also with mGlu5 receptors or other targets, as they observed neuroprotective effect at concentrations 300-fold higher than those known to interact with mGlu1 receptors, but their opinion was based on the data obtained in vitro after 3-NP toxicity whereas we used cultures exposed to KA-induced excitotoxicity, so the models were different. 

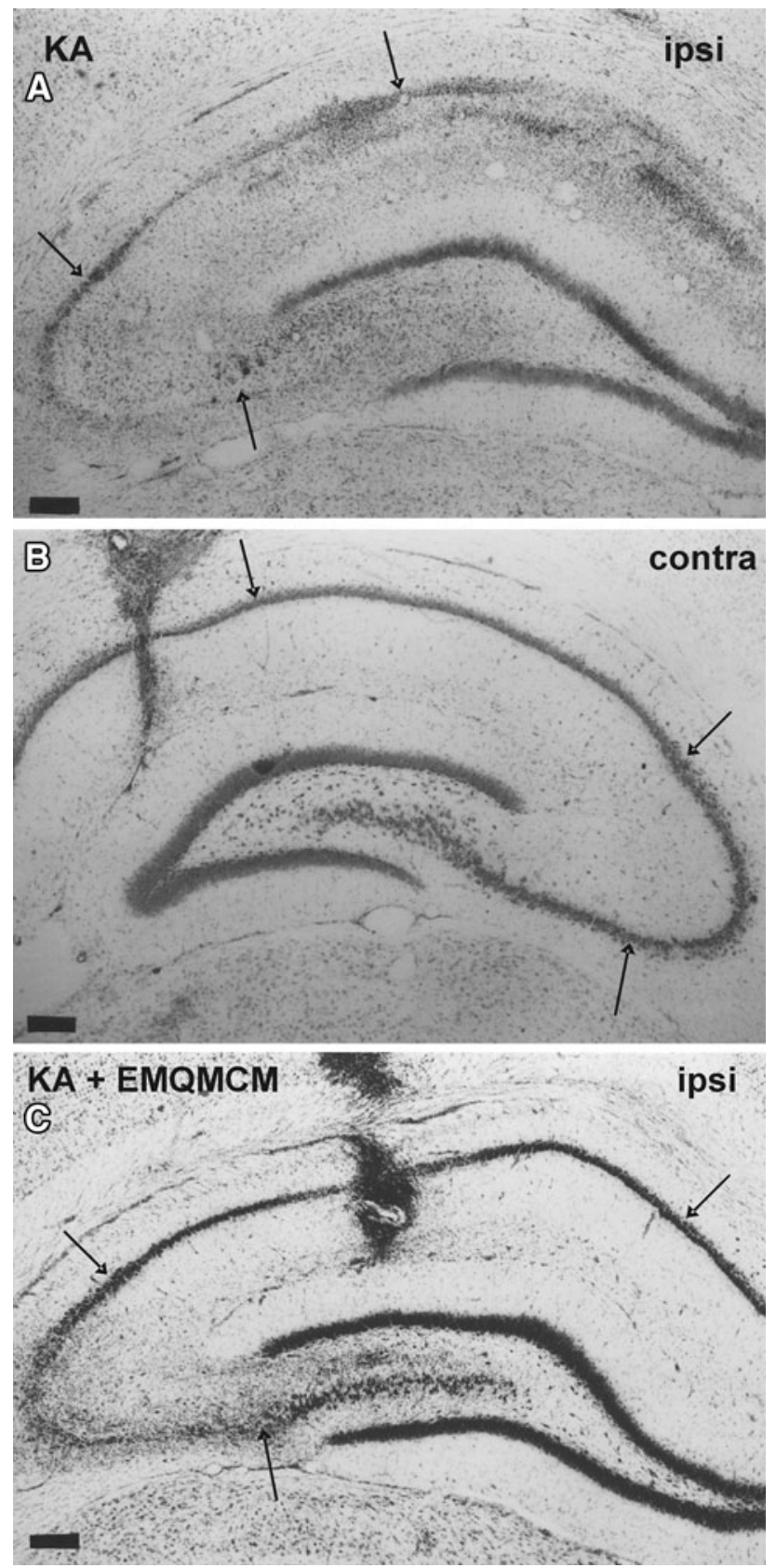

Fig. 3 Microphotographs of frontal sections of rat brain hippocampi stained with cresyl violet. Pyramidal layer of CA regions is pointed by arrows. Calibrations bars $200 \mu \mathrm{m}$. a Loss of neurons and extensive gliosis is seen in CA after KA microinjection $(2.5 \mu \mathrm{m} / 1 \mu \mathrm{l})$. b Contralateral hippocampus is not degenerated. A small glial scar only is seen in the site of the buffer injection. c Neuroprotective effect of EMQMCM $(10 \mathrm{nmol})$ injected into the hippocampus $3 \mathrm{~h}$ after KA. The lesion is much smaller than after KA alone

On the other hand, concentrations used in our studies both in vitro and in vivo are similar to those used in our previous experiments with mGluR5 antagonist, MTEP (Domin et al. 2006, 2010) and the strong enhancement in GABA release, found after EMQMCM in microdialysis studies, corresponds well to the results obtained by other authors after

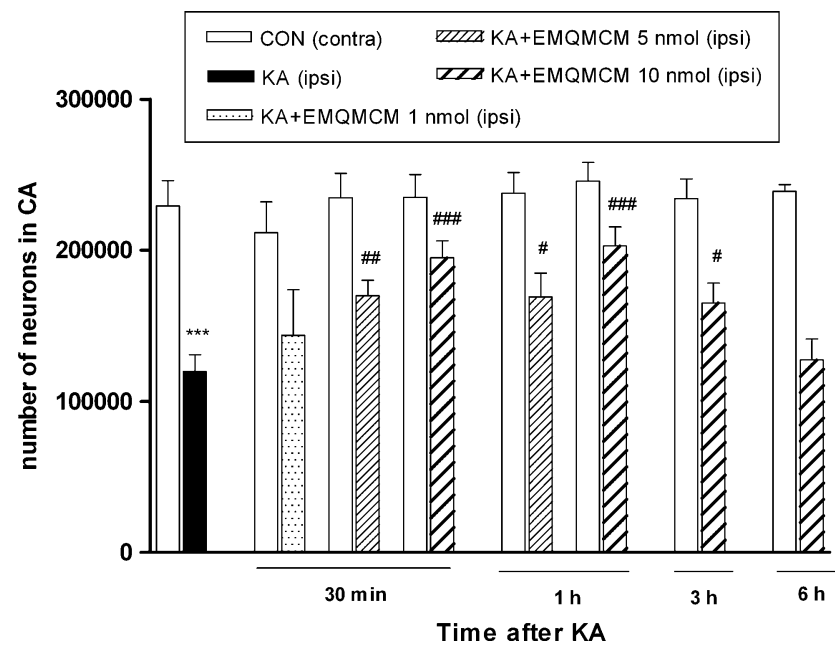

Fig. 4 The effect of intrahippocampal injections of KA $(2.5 \mathrm{nmol} /$ $1 \mu \mathrm{l})$ and $\mathrm{KA}$ followed by EMQMCM on the number of neurons in the pyramidal layer of $\mathrm{CA}$ regions. The results of stereological counting showed neurodegeneration after KA (50\% loss) and neuroprotection induced by EMQMCM given $30 \mathrm{~min}, 1 \mathrm{~h}$, or $3 \mathrm{~h}$ after KA. No protection was seen when EMQMCM was given $6 \mathrm{~h}$ after KA. Each bar represents the mean \pm SEM of $n=6$ per group. ${ }^{* * *} P<0.001 \mathrm{KA}$ (ipsilateral) versus contralateral side; ${ }^{\#} P<0.05$, ${ }^{\# \#} P<0.01, \quad{ }^{\# \#} P<0.001 \mathrm{KA}+\mathrm{EMQMCM}$ (ipsilateral) versus KA-lesioned (ipsilateral) hippocampi

other mGluR1 antagonists which was postulated to be characteristic of these compounds (Battaglia et al. 2001; Cozzi et al. 2002). Therefore, all our results indicate that the effects observed in this study are at least in majority dependent on the interaction with mGluR1.

A new and important finding of our present study is the observation that EMQMCM may be neuroprotective after delayed application. In most of other studies, mGluR1 antagonists were given simultaneously or 30-120 min after the onset of neurodegenerative treatment. EMQMCM was found to be neuroprotective in the ischemic model when given $2 \mathrm{~h}$ after the onset of ischemia (Szydlowska et al. 2007) or just immediately after hypoxia-ischemia (Makarewicz et al. 2006). Also other mGluR1 antagonists were given before, simultaneously or soon after the NMDA excitotoxicity, ischemia, or trauma (Bruno et al. 1999; Pellegrini-Giampietro et al. 1999; Rao et al. 2000; Faden et al. 2001; Cozzi et al. 2002; Kohara et al. 2008; Murotomi et al. 2008). In our present study, EMQMCM was effective even if it was applied $6 \mathrm{~h}$ after the onset of KA intoxication in the in vitro neuronal cultures, or after $3 \mathrm{~h}$ in the in vivo experiments with intrahippocampal injection. The efficacy of such delayed treatment seems to be valuable and important.

The model of neurodegeneration used in our present study was based on kainic acid-induced excitotoxicity. It seems that the KA model may give better possibilities for studying delayed neuroprotection than models based on 

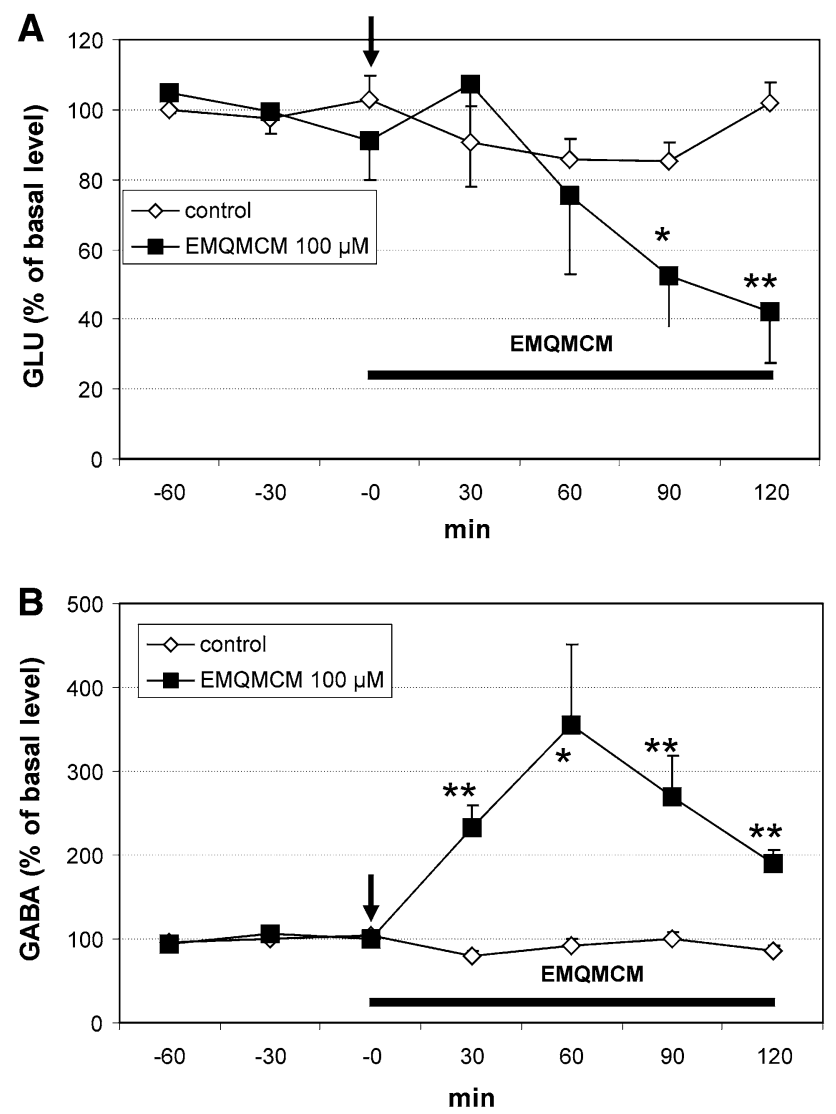

Fig. 5 Effect of EMQMCM $(100 \mu \mathrm{M})$ on extracellular GLU (a) and GABA (b) level in the rat hippocampus. EMQMCM administration is indicated with an arrow, while horizontal bar shows duration of treatment. Data are means \pm SEM $(n=4-10)$. Repeated measures ANOVA and Tukey's post hoc test. $* P<0.05$, $* * P<0.01$ in comparison with control

selective activation of ionotropic NMDA receptors. As mentioned above in "Introduction," the effect of KA develops progressively, and endogenous glutamate gradually released from overexcited neurons enhances degeneration. Also in our earlier studies (Domin et al. 2006) with the KA-excitotoxicity model, we demonstrated both gradual increase in caspase-3 activity, with the maximum at $6 \mathrm{~h}$ after the KA treatment and then LDH release with maximum 24-48 $\mathrm{h}$ after the KA administration. Moreover, the KA-model seems to be somewhat similar to a stroke or trauma observed in patients in which besides the primarily degenerated core region with rapidly dying cells there is a wide penumbra zone where cells can be salvaged within several hours. Effectiveness of neuroprotection after delayed treatment, found in our studies together with the findings that EMQMCM may be protective also after systemic injection (Makarewicz et al. 2006; Szydlowska et al. 2007) may inspire hope that such compound might diminish the penumbra.

Our present in vitro results indicate that the neuroprotective action of EMQMCM can be at least partially
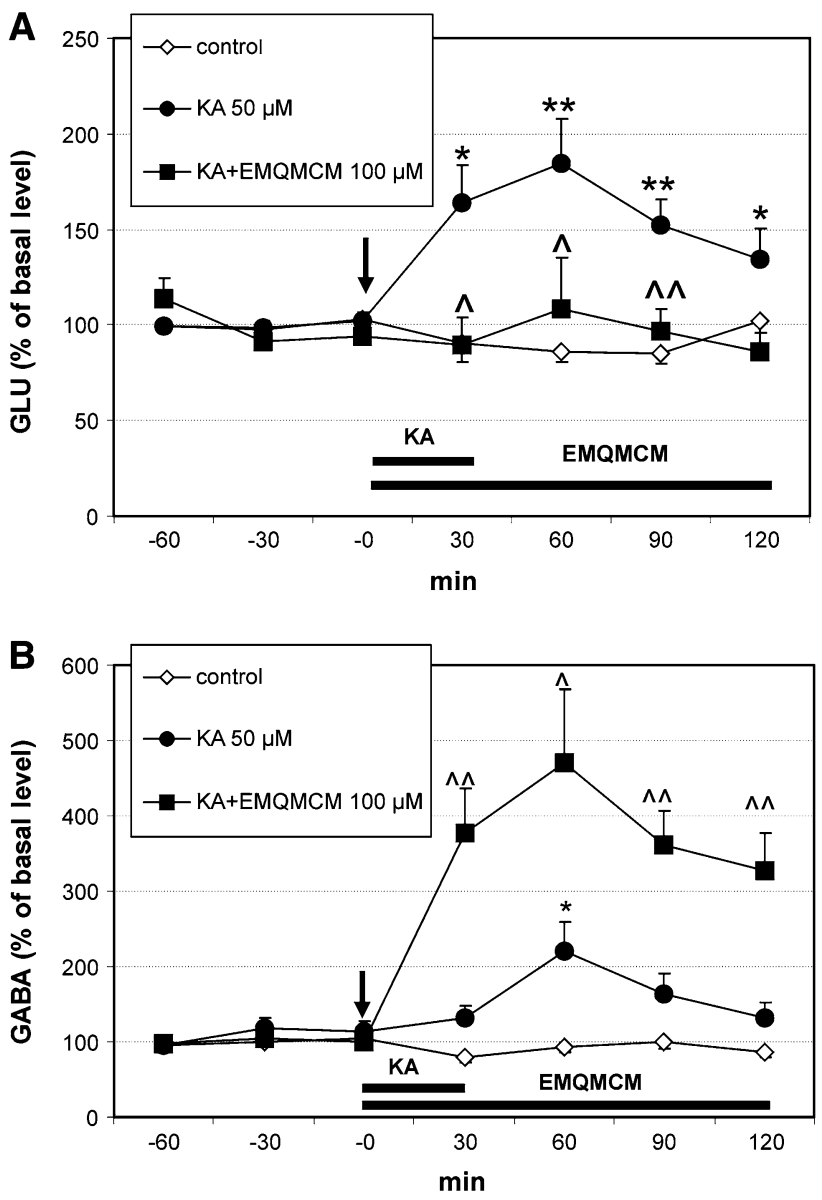

Fig. 6 Effect of EMQMCM $(100 \mu \mathrm{M})$ and kainic acid (KA $50 \mu \mathrm{M})$ on extracellular GLU (a) and GABA (b) level in the rat hippocampus. EMQMCM and KA administration is indicated with an arrow, while horizontal bar shows duration of treatment. Data are means \pm SEM $(n=4-10)$. Repeated measures ANOVA and Tukey's post hoc test. $* P<0.05, * * P<0.01$ in comparison with control; ${ }^{\wedge} P<0.05$, ${ }^{\wedge} \wedge P<0.01$ in comparison to group treated with $\mathrm{KA}$

attributed to the reduction of apoptosis, as it decreased the KA-induced caspase- 3 activation. The caspase- 3 activation is a good marker of apoptosis used for quantitative analysis. Schedule in this experiment was based on our previous studies concerning the neuroprotective action of the mGluR5 antagonist MTEP (Domin et al. 2006). Our present finding is quite a new one because till now there have been a few papers only concerning the influence of mGluR1 ligands on apoptosis (and no studies concerning EMQMCM). Based on the spinal cord neuropathic model Siniscalco et al. (2008) found an antiapoptotic effect of the mGluR1 antagonist JNJ16259685 in the spinal dorsal horn using TUNEL and immunohistochemical methods. In contrast, Allen et al. (2000), using the in vitro ischemic models, showed that mGluR1 activation was connected mainly with necrotic cell death and the inhibition of these receptors attenuated necrosis. Our results demonstrate a strong antiapoptotic effect of EMQMCM. The KA-induced 
increase in caspase- 3 activity was entirely blocked by the compound in all concentrations studied $(0.1-100 \mu \mathrm{M})$. The effect of EMQMCM on the apoptosis was evidenced not only by means of caspase-3 measurements but also by microscopic observations of cultures stained by Hoechst method in which density of apoptotic bodies clearly decreased after the drug addition. The microscopic observations were not quantified but were an additional illustration visualizing the actual apoptosis corresponding with quantitative results obtained by caspase- 3 activity measurements.

To study the mechanism of neuroprotective action of EMQMCM, the microdialysis method was used. We investigated the effects of EMQMCM on glutamate and GABA release in the hippocampus of freely moving rats. The results show a strong enhancement of GABA release after the drug treatment while the level of extracellular glutamate was decreased. Analysis of the time courses of changes in GABA and glutamate level in the perfusates suggests that the primary effect of EMQMCM involves the action on GABA as its level increases immediately after the drug application and peaks after $60 \mathrm{~min}$, while the decreasing effect on glutamate seems to be secondary, starting at $60 \mathrm{~min}$ and reaching significance at 90 and $120 \mathrm{~min}$ after application.

KA induced a tremendous increase in the glutamate release shortly after the toxin application, and a weaker increase in the GABA level which appeared later. KA in microdialysis was used in lower concentration than in in vitro experiments. The preliminary studies indicated that $50-\mu \mathrm{M}$ KA did not induce seizures while it markedly affected glutamate release. EMQMCM co-administered with KA strongly enhanced the KA-induced GABA release; the values were about twice higher than KA alone. At the same time EMQMCM prevented the KA-stimulated glutamate release. A significant regulating effect of EMQMCM on GABAergic and glutamatergic function may be connected with anatomical distribution of its target receptors. It has been found that mGlu1 receptors are extensively expressed throughout the brain with medium to high levels in some cortical and hippocampal regions (Spooren et al. 2003) and are localized mainly postsynaptically but also presynaptically (Ferraguti et al. 2008). In the hippocampus, mGlu1 receptors are expressed mainly in GABA interneurons but also in principal glutamatergic neurons (Shigemoto et al. 1997; Ferraguti et al. 2008), and a modulation of GABAergic transmission has been postulated (Speed and Dobrunz 2008). Presynaptic mGlu1 autoreceptors on glutamatergic terminals were found in the mouse cerebral cortex (Musante et al. 2008).

There are no studies yet on the influence of EMQMCM on GABA and glutamate output in brain structures, but the results obtained with other mGluR1 antagonists are generally in line with our findings. Pellegrini-Giampietro et al. (1999) using a microdialysis study in freely moving gerbils showed a highly significant increase in the concentration of GABA in hippocampal dialysates, but no changes in glutamate, after the mGluR1 antagonist, AIDA treatment. The reason of the discrepancy concerning glutamate may arise from the fact that the cited authors used a much shorter time of experiment than we did; they perfused the hippocampus with AIDA for 9 min only and collected the perfusate immediately after the treatment whereas the effect on glutamate release appeared in our experiments much later, 90 and $120 \mathrm{~min}$ after the perfusion onset and was probably a secondary effect. Moreover, these authors studied the effect of AIDA alone but did not examine whether it changed the effects of excitatory compounds on amino acids release, so our results provide a much more complex information. The longer time of experiment was used by Cozzi et al. (2002), namely the antagonists, AIDA and CBPG, perfused for $60 \mathrm{~min}$, protected pyramidal CA1 neurons in gerbils' hippocampus subjected to global ischemia and induced substantial increase in GABA release and minor elevation of glutamate output. Another research group, Battaglia et al. (2001), using microdialysis in the rat striatum, studied the effect of two mGluR1 antagonists: competitive LY367385 and uncompetitive CPCCOEt during a 20-min perfusion on NMDA-induced release of glutamate and found no effect or even increase in the level of glutamate in the striatal perfusate. At the same time, GABA release was substantially enhanced. Different results were obtained during the microdialysis of rat periaqueductal gray where CPCCOEt (a selective mGluR1 antagonist) given alone did not change the GABA or glutamate release but antagonized the release of these amino acids induced by DHPG (a group I mGluR agonist) (de Novellis et al. 2003). Therefore, all those findings show that a selective blockade of mGlu1 receptors produces the enhancement in GABAergic transmission which is in line with our present results. Moreover, the results of Cozzi et al. (2002) suggested an important role of GABA activation in the neuroprotective effects of studied mGluR1 antagonists, as the protection was reduced by GABA receptor antagonists and was mimicked by GABA and GABA receptor agonists.

In conclusion, the results obtained in this study demonstrated significant neuroprotective effects of the mGluR1 antagonist EMQMCM in excitotoxicity. Neuroprotection evoked by EMQMCM may arise from an enhancement of inhibitory GABAergic transmission and a suppression of excitatory glutamatergic transmission. It seems to be important that the compound reveals its protective activity even when the treatment is delayed by up to 3-6 h after the intoxication onset, which may give us a hope for future therapeutic use of similar compounds in patients to whom the neuroprotective treatment can be applied a few hours after damage. 
Acknowledgments The study was supported by the KBN Grant No. 2P05A 11428 , also by funds for statutory activity of the Institute of Pharmacology, Polish Academy of Sciences, Krakow, Poland and by MS\&HE scientific network 28/E-32/SN-0053/2007.

Open Access This article is distributed under the terms of the Creative Commons Attribution Noncommercial License which permits any noncommercial use, distribution, and reproduction in any medium, provided the original author(s) and source are credited.

\section{References}

Allen JW, Knoblach SM, Faden AI (2000) Activation of group I metabotropic glutamate receptors reduces neuronal apoptosis but increases necrotic cell death in vitro. Cell Death Differ 7:470-476

Bao WL, Williams AJ, Faden AI, Tortella FC (2001) Selective mGluR5 receptor antagonist or agonist provides neuroprotection in a rat model of focal cerebral ischemia. Brain Res 922:173-179

Battaglia G, Bruno V, Pisani A, Centonie D, Catania MV, Calabresi P, Nicoletti F (2001) Selective blockade of type-1 metabotropic glutamate receptors induces neuroprotection by enhancing GABAergic transmission. Mol Cell Neurosci 17:1071-1083

Belozertseva IV, Kos T, Popik P, Danysz W, Bespalov AY (2007) Antidepressant-like effects of mGluR1 and mGluR5 antagonists in the rat forced swim and the mouse tail suspension tests. Eur Neuropsychopharmacol 17:172-179

Brewer GJ (1995) Serum-free B27/neurobasal medium supports differentiated growth of neurones from the striatum, substantia nigra, septum, cerebral cortex, cerebellum and dentate gyrus. J Neurosci Res 42:674-683

Bruno V, Copani A, Knöpfel T, Kuhn R, Casabona G, Dell'Albani P, Condorelli DF, Nicoletti F (1995) Activation of metabotropic glutamate receptors coupled to inositol phospholipid hydrolysis amplifies NMDA-induced neuronal degeneration in cultured cortical cells. Neuropharmacology 34:1089-1098

Bruno V, Copani A, Bonanno L, Knoepfel T, Kuhn R, Roberts PJ, Nicoletti F (1996) Activation of group III metabotropic glutamate receptors is neuroprotective in cortical cultures. Eur $\mathrm{J}$ Pharmacol 310:61-66

Bruno V, Sureda FX, Storto M, Casabona G, Caruso A, Knopfel T, Kuhn R, Nicoletti F (1997) The neuroprotective activity of group-II metabotropic glutamate receptors requires new protein synthesis and involves a glial-neuronal signaling. J Neurosci 17:1891-1897

Bruno V, Battaglia G, Kingston A, O’Neill MJ, Catania MV, Di Grezia R, Nicoletti F (1999) Neuroprotective activity of the potent and selective mGlula metabotropic glutamate receptor antagonist, (+)-2-methyl-4-carboxyphenylglycine (LY367385): comparison with LY 357366, a broader spectrum antagonist with equal affinity for mGlu1a and mGlu5 receptors. Neuropharmacology 38:199-207

Bruno V, Ksiazek I, Battaglia G, Lukic S, Leonhardt T, Sauer D, Gasparini F, Kuhn R, Nicoletti F, Flor PJ (2000) Selective blockade of metabotropic glutamate receptor subtype 5 is neuroprotective. Neuropharmacology 39:2223-2230

Bruno V, Battaglia G, Copani A, D'Onofrio M, Di Iorio P, De Blasi A, Melchiorri D, Flor PJ, Nicoletti F (2001) Metabotropic glutamate receptor subtypes as targets for neuroprotective drugs. J Cereb Blood Flow Metab 21:1013-1033

Byrnes KR, Loane DJ, Faden AI (2009) Metabotropic glutamate receptors as targets for multipotential treatment of neurological disorders. Neurotherapeutics 6:94-107
Choi DW (1988) Glutamate neurotoxicity and diseases of the nervous system. Neuron 1:623-634

Choi DW (1994) Glutamate receptors and the induction of excitotoxic neuronal death. Prog Brain Res 100:47-51

Conn PJ, Pin JP (1997) Pharmacology and functions of metabotropic glutamate receptors. Annu Rev Pharmacol Toxicol 37:205-237

Copani A, Bruno VM, Barresi V, Battaglia G, Condorelli DF, Nicoletti F (1995) Activation of metabotropic glutamate receptors prevents neuronal apoptosis in culture. $\mathrm{J}$ Neurochem 64:101-108

Coyle JT (1983) Neurotoxic action of kainic acid. J Neurochem 41:1-11

Cozzi A, Meli E, Carlà V, Pellicciari R, Moroni F, PellegriniGiampietro DE (2002) Metabotropic glutamate 1 (mGlu1) receptor antagonists enhance GABAergic neurotransmission: a mechanism for the attenuation of post-ischemic injury and epileptiform activity? Neuropharmacology 43:119-130

Danysz W, Parsons CG (1998) Glycine and N-methyl-D-aspartate receptors: physiological significance and possible therapeutic applications. Pharmacol Rev 50:597-664

de Novellis V, Marabese I, Palazzo E, Rossi F, Berrino L, Rodella L, Bianchi R, Rossi F, Maione S (2003) Group I metabotropic glutamate receptors modulate glutamate and gamma-aminobutyric acid release in the periaqueductal grey of rats. Eur $\mathrm{J}$ Pharmacol 462:73-81

Domin H, Kajta M, Smiałowska M (2006) Neuroprotective effects of MTEP, a selective mGluR5 antagonists and neuropeptide $\mathrm{Y}$ on the kainate-induced toxicity in primary neuronal cultures. Pharmacol Rep 58:846-858

Domin H, Zięba B, Gołembiowska K, Kowalska M, Dziubina A, Śmiałowska M (2010) Neuroprotective potential of mGluR5 antagonist MTEP: effects on kainate-induced excitotoxicity in the rat hippocampus. Pharmacol Rep 62:1051-1061

Faden AI, O'Leary DM, Fan L, Bao W, Mullis PGM, Movsesyan VA (2001) Selective blockade of the mGluR1 receptor reduces traumatic neuronal injury in vitro and improves outcome after brain trauma. Exp Neurol 167:435-444

Ferkany JW, Coyle JT (1983) Kainic acid selectively stimulates the release of endogenous excitatory acidic amino acids. J Pharmacol Exp Ther 225:399-406

Ferkany JW, Zaczek R, Coyle JT (1982) Kainic acid stimulates excitatory amino acid neurotransmitter release at presynaptic receptors. Nature 298:757-759

Ferraguti F, Crepaldi L, Nicoletti F (2008) Metabotropic glutamate 1 receptor: current concepts and perspectives. Pharmacol Rev 60:536-581

Flor PJ, Battaglia G, Nicoletti F, Gasparini F, Bruno V (2002) Neuroprotective activity of metabotropic glutamate receptor ligands. Adv Exp Med Biol 513:197-223

Gasparini F, Bruno V, Battaglia G, Lukic S, Leonhardt T, Inderbitzin W, Laurie D, Sommer B, Varney MA, Hess SD, Johnson EC, Kuhn R, Urwyler S, Sauer D, Portet C, Schmutz M, Nicoletti F, Flor PJ (1999) (R,S)-4-phosphonophenylglycine, a potent and selective group III metabotropic glutamate receptor agonist, is anticonvulsive and neuroprotective in vivo. J Pharmacol Exp Ther 289:1678-1687

Gołembiowska K, Dziubina A (2004a) Effect of the adenosine A2A receptor antagonist 8-(3-chlorostyryl)caffeine on L-DOPA biotransformation in rat striatum. Brain Res 998:208-217

Gołembiowska K, Dziubina A (2004b) Striatal adenosine A(2A) receptor blockade increases extracellular dopamine release following 1-DOPA administration in intact and dopaminedenervated rats. Neuropharmacology 47:414-426

Gravius A, Pietraszek M, Schäfer D, Schmidt WJ, Danysz W (2005) Effects of mGlu1 and mGlu5 receptor antagonists on negatively reinforced learning. Behav Pharmacol 16:113-121 
Gundersen HJ, Jensen EB (1987) The efficiency of systematic sampling in stereology and its prediction. J Microsc 147:229-263

Ikonomidou C, Turski L (2002) Why did NMDA receptor antagonists fail clinical trials for stroke and traumatic brain injury? Lancet Neurol 1:383-386

Kajta M, Lasoń W (2000) Oestrogen effects on kainate-induced toxicity in primary cultures of rat cortical neurons. Acta Neurobiol Exp (Wars) 60:365-369

Kajta M, Budziszewska B, Lasoń W (1999) Allopregnanolone attenuates kainate-induced toxicity in primary cortical neurons and PC12 neuronal cells. Pol J Pharmacol 51:531-534

Kajta M, Lasoń W, Kupiec T (2004) Effects of estrone on N-methylD-aspartic acid- and staurosporine-induced changes in caspase-3like protease activity and lactate dehydrogenase-release: time and tissue-dependent effects in neuronal cultures. Neuroscience 123:515-526

Kajta M, Trotter A, Lasoń W, Beyer C (2005) Effect of NMDA on staurosporine-induced activation of caspase-3 and LDH release in mouse neocortical and hippocampal cells. Brain Res Dev Brain Res 160:40-52

Kajta M, Domin H, Grynkiewicz G, Lason W (2007) Genistein inhibits glutamate-induced apoptotic processes in primary neuronal cell cultures: an involvement of aryl hydrocarbon receptor and estrogen receptor/glycogen synthase kinase-3beta intracellular signaling pathway. Neuroscience 145:592-604

Knecht R, Chang JY (1986) Liquid chromatographic determination of amino acids after gas-phase hydrolysis and derivatization with (dimethylamino)azobenzenesulfonyl chloride. Anal Chem 58:2375-2379

Kohara A, Takahashi M, Yatsugi S, Tamura S, Shitaka Y, Hayashibe S, Kawabata S, Okada M (2008) Neuroprotective effects of the selective type 1 metabotropic glutamate receptor antagonist YM-202074 in rat stroke models. Brain Res 1191:168-179

Kotlinska J, Bochenski M (2008) The influence of various glutamate receptors antagonists on anxiety-like effect of ethanol withdrawal in a plus-maze test in rats. Eur J Pharmacol 598:57-63

Lea PM IV, Movsesyan VA, Faden AI (2005) Neuroprotective activity of the mGluR5 antagonists MPEP and MTEP against acute excitotoxicity differs and does not reflect actions at mGluR5 receptors. Br J Pharmacol 145:527-534

Lesage ASJ, Bischoff F, Van Beijsterveldt L, Meert T, Steckler T, Ashton D (2002) Novel, centrally active mGlu1 antagonists: in vitro and in vivo pharmacology. Neuropharmacology 43:295

Liu W, Liu R, Chun JT, Bi R, Hoe W, Schreiber SS, Baudry M (2001) Kainate excitotoxicity in organotypic hippocampal slice cultures: evidence for multiple apoptotic pathways. Brain Res 916:239-248

Makarewicz D, Duszczyk M, Gadamski R, Danysz W, Łazarewicz JW (2006) Neuroprotective potential of group I metabotropic glutamate receptor antagonists in two ischemic models. Neurochem Int 48:485-490

Mazzone GL, Nistri A (2011) Delayed neuroprotection by riluzole against excitotoxic damage evoked by kainate on rat organotypic spinal cord cultures. Neuroscience. doi: 10.1016/j.neuroscience. 2011.06.013

Mazzone GL, Margaryan G, Kuzhandaivel A, Nasrabady SE, Mladinic M, Nistri A (2010) Kainate-induced delayed onset of excitotoxicity with functional loss unrelated to the extent of neuronal damage in the in vitro spinal cord. Neuroscience 168:451-462

McGeer EG, McGeer PL, Singh K (1978) Kainate-induced degeneration of neostriatal neurons: dependency upon corticostriatal tract. Brain Res 139:381-383

Muir KW, Lees KR (1995) Clinical experience with excitatory amino acid antagonist drugs. Stroke 26:503-513
Murotomi K, Takagi N, Takayanagi G, Ono M, Takeo S, Tanonaka K (2008) mGluR1 antagonist decreases tyrosine phosphorylation on NMDA receptor and attenuates infarct size after transient focal cerebral ischemia. J Neurochem 105:1625-1634

Musante V, Neri E, Feligioni M, Puliti A, Pedrazzi M, Conti V, Usai C, Diaspro A, Ravazzolo R, Henley JM, Battaglia G, Pittaluga A (2008) Presynaptic mGlu1 and mGlu5 autoreceptors facilitate glutamate exocytosis from mouse cortical nerve endings. Neuropharmacology 55:474-482

Nicholson DW, Ali A, Thornberry NA, Vaillancourt JP, Ding CK, Gallant M, Gareau Y, Griffin PR, Labelle M, Lazebnik YA et al (1995) Identification and inhibition of the ICE/CED-3 protease necessary for mammalian apoptosis. Nature 376:37-43

Nicoletti F, Bruno V, Copani A, Casabona G, Knöpfel T (1996) Metabotropic glutamate receptors: a new target for the therapy of neurodegenerative disorders? Trends Neurosci 19:267-271

Nicoletti F, Bruno V, Catania MV, Battaglia G, Copani A, Barbagallo G, Ceña V, Sanchez-Prieto J, Spano PF, Pizzi M (1999) Group-I metabotropic glutamate receptors: hypotheses to explain their dual role in neurotoxicity and neuroprotection. Neuropharmacology 38:1477-1484

Olney JW (1978) Neurotoxicity of excitatory amino acids. In: McGeer EG, Olney JW, McGeer PL (eds) Kainic acid as a tool in neurobiology. Raven Press, New York, pp 95-112

Olney JW, Ishimaru MJ (1999) Excitotoxic cell death. In: Koliatsos VE, Ratan RR (eds) Cell death and diseases in the nervous system. Humana Press, Totowa, pp 197-220

Ossowska K, Wardas J, Śmiałowska M, Kuter K, Lenda T, Wierońska JM, Zieba B, Nowak P, Dabrowska J, Bortel A, Kwieciński A, Wolfarth S (2005) A slowly developing dysfunction of dopaminergic nigrostriatal neurons induced by long-term paraquat administration in rats: an animal model of preclinical stages of Parkinson's disease? Eur J Neurosci 22:1294-1304

Ossowska K, Śmiałowska M, Kuter K, Wierońska J, Zieba B, Wardas J, Nowak P, Dabrowska J, Bortel A, Biedka I, Schulze G, Rommelspacher H (2006) Degeneration of dopaminergic mesocortical neurons and activation of compensatory processes induced by a long-term paraquat administration in rats: implications for Parkinson's disease. Neuroscience 141:2155-2165

Paxinos G, Watson C (1986) The rat brain in stereotaxic coordinates, 2nd edn. Academic Press, San Diego

Pellegrini-Giampietro DE, Peruginelli F, Meli E, Cozzi A, AlbaniTorregrossa S, Pellicciari R, Moroni F (1999) Protection with metabotropic glutamate 1 receptor antagonists in models of ischemic neuronal death: time-course and mechanisms. Neuropharmacology 38:1607-1619

Pietraszek M, Sukhanov I, Maciejak P, Szyndler J, Gravius A, Wasłowska A, Płaźnik A, Bespalov AY, Danysz W (2005) Anxiolytic-like effects of mGlu1 and mGlu5 receptor antagonists in rats. Eur J Pharmacol 514:25-34

Pin JP, Duvoisin R (1995) The metabotropic glutamate receptors: structure and functions. Neuropharmacology 34:1-26

Popoli P, Pintor A, Tebano MT, Frank C, Pepponi R, Nazzicone V, Grieco R, Pèzzola A, Reggio R, Minghetti L, De Berardinis MA, Martire A, Potenza RL, Domenici MR, Massotti M (2004) Neuroprotective effects of the mGlu5R antagonist MPEP towards quinolinic acid-induced striatal toxicity: involvement of pre- and post-synaptic mechanisms and lack of direct NMDA blocking activity. J Neurochem 89:1479-1489

Rao AM, Hatcher JF, Dempsey RJ (2000) Neuroprotection by group I metabotropic glutamate receptor antagonists in forebrain ischemia of gerbil. Neurosci Lett 293:1-4

Shigemoto R, Kinoshita A, Wada E, Nomura S, Ohishi H, Takada M, Flor PJ, Neki A, Abe T, Nakanishi S, Mizuno N (1997) Differential presynaptic localization of metabotropic glutamate 
receptor subtypes in the rat hippocampus. J Neurosci 17:7503-7522

Shih YH, Wu SL, Chiou WF, Ku HH, Ko TL, Fu YS (2002) Protective effects of tetramethylpyrazine on kainate-induced excitotoxicity in hippocampal culture. Neuroreport 13:515-519

Shih YH, Chein YC, Wang JY, Fu YS (2004) Ursolic acid protects hippocampal neurons against kainate-induced excitotoxicity in rats. Neurosci Lett 362:136-140

Siniscalco D, Giordano C, Fuccio C, Luongo L, Ferraraccio F, Rossi F, de Novellis V, Roth KA, Maione S (2008) Involvement of subtype 1 metabotropic glutamate receptors in apoptosis and caspase-7 over-expression in spinal cord of neuropathic rats. Pharmacol Res 57:223-233

Śmiałowska M, Wierońska JM, Szewczyk B (2003) Neuroprotective effect of NPY on kainate neurotoxicity in the hippocampus. Pol J Pharmacol 55:979-986

Śmiałowska M, Domin H, Zieba B, Koźniewska E, Michalik R, Piotrowski P, Kajta M (2009) Neuroprotective effects of neuropeptide Y-Y2 and Y5 receptor agonists in vitro and in vivo. Neuropeptides 43:235-249

Speed HE, Dobrunz LE (2008) Developmental decrease in short-term facilitation at Schaffer collateral synapses in hippocampus is mGluR1 sensitive. J Neurophysiol 99:799-813

Spooren W, Ballard T, Gasparini F, Amalric M, Mutel V, Schreiber R (2003) Insight into the function of Group I and Group II metabotropic glutamate (mGlu) receptors: behavioural characterization and implications for the treatment of CNS disorders. Behav Pharmacol 14:257-277

Szydlowska K, Kaminska B, Baude A, Parsons CG, Danysz W (2007) Neuroprotective activity of selective mGlu1 and mGlu5 antagonists in vitro and in vivo. Eur J Pharmacol 554:18-29

Wang Q, Yu S, Simonyi A, Sun GY, Sun AY (2005) Kainic acidmediated excitotoxicity as a model for neurodegeneration. Mol Neurobiol 31:3-16

Watkins JC, Evans RH (1981) Excitatory amino acid transmitters. Annu Rev Pharmacol Toxicol 21:165-204 